Original Research paper

\title{
Relationship Between Antibodies to Toxocara and the Disability of the Human Ankylosing Spondylitis
}

\author{
${ }^{1}$ Francisco-Javier Jiménez-Balderas, ${ }^{2}$ Patricia Méndez-Samperio, \\ ${ }^{3}$ Raquel Tapia-Romero and ${ }^{4}$ Jorge-Luis de-la-Rosa-Arana \\ ${ }^{1}$ Centro Médico Nacional Siglo XXI, Instituto Mexicano del Seguro Social, México D.F., Mexico \\ ${ }^{2}$ Escuela Nacional de Ciencias Biológicas, Instituto Politécnico Nacional, México D.F., México \\ ${ }^{3}$ Hospital Infantil de México, Secretaría de Salud. México D.F., México \\ ${ }^{4}$ Instituto de Diagnóstico y Referencia Epidemiológicos, Secretaría de Salud, México D.F., México
}

\section{Article history}

Received: 31-12-2014

Revised: 04-01-2015

Accepted: 28-04-2015

Corresponding Author: Jorge-Luis de-la-Rosa-Arana Laboratorio de

Inmunoparasitología, Instituto de Diagnóstico y Referencia Epidemiológicos. Secretaría de Salud. Francisco de Paula Miranda 177, México D.F. 01480, México

Tel: + 525550621600 ext. 59349

Email: jorgeluis.delarosa@yahoo.com

\begin{abstract}
There are only few studies reported in the literature of patients with spondyloarthropathies associated with Toxocara infection. Thus, the aim of this work was to investigate the relationship between antibodies to Toxocara and the disability of the human Ankylosing Spondylitis (AS). Thirty-six AS patients (14 female and 22 male) participated during the study period and all were residents from Mexico City. Evaluations included physician and patient self-assessment Bath Ankylosing Spondylitis Functional Index (BASFI) to define the joint limitation of the spine. Blood tests included the identification of Human Leukocyte Antigen B27 (HLAB27), Erythrocyte Sedimentation Rate (ESR), levels of C-Reactive Protein (CRP) and levels of antibodies to Toxocara canis and Ascaris lumbricoides. Seventy seven serum samples of healthy donors were used as control group. Seropositivity for $T$. canis was detected in $25 \%$ of patients with AS and 1/36 was positive for antibodies to Ascaris while, 2/77 were positive for Toxocara and 1/77 for Ascaris in the control group. A correlation between antibodies to Toxocara and the presence of AS was observed ( $p=0.0005432$; Mid-P exact, two tails); the levels of antibodies to Toxocara were not associated with the HLA-B-57 antigen neither with the disability caused by the AS, although the $74 \%$ of AS patients had high values of BASFI $(6.4 \pm 1.5)$ with normal levels of CRP and ESR. In addition, no significant difference was observed between the AS patients and control group in the seropositivity for Ascaris $(\mathrm{p}=0.64)$. These results suggest a minor role for toxocariosis in the AS limited joint in Mexican population, however further studies are needed to determine the role of Toxocara in the AS prognosis.
\end{abstract}

Keywords: Ankylosing-spondylitis, Toxocara, Antibodies, Mexico

\section{Introduction}

Ankylosing Spondylitis (AS) is an inflammatory disease of unknown etiology, affecting mainly the axial skeleton and adjacent structures as well as involvement of multiple organs including the eyes, lungs and heart (Sieper et al., 2006; Zochling, 2008). In addition, AS is the most severe subtype of spondyloarthritis (Anderson et al., 2001). Although several studies have described the relationship between disease activity in patients with AS and bacterial infections, including infections by
Salmonella (Paul et al., 1988; Martínez et al., 2004) and Yersinia (Yli-Kerttula et al., 1995), there are few reported cases of rheumatic syndromes associated with parasitic infections (Bocanegra and Vasey, 1993; Peng, 2002). In this regard, it has been demonstrated arthritis associated to the infection by the nematode Toxocara (Williams and Roy, 1981; Kuk et al., 2006; Jiménez-Balderas et al., 2012). The main species that causes human toxocariosis are $T$. canis and T. cati, the former associated to dogs and the second to cats. The adult worm lives in the intestinal gut of puppies and, the excrete eggs become infective in the soil after 1-3 weeks. 
Humans become infected by oral ingestion of the infectious eggs (Magnaval et al., 2001). A high prevalence of antibodies to Toxocara has been found in countries where the dog population is abundant (Oge and Oge, 2000; Radman et al., 2000). In Mexico, dogs and cats are commonly used as pets (Romero-Núñez et al., 2013). Since many patients with active AS are dog owners, our aim was to investigate whether there is a relationship between antibodies to Toxocara and the disability of the ankylosing spondylitis in Mexican patients.

\section{Materials and Methods}

\section{Subjects}

The present study enrolled 36 consecutive adult patients (14 female and 22 male; mean \pm SD age: $39.7 \pm 15.1$ years) with a diagnosis of definite AS. Patients were clinically diagnosed in a tertiary health care hospital. All patients fulfilled the 1984 modified New York criteria for diagnosis of AS (Calin et al., 1994; Garrett et al., 1994) and completed questionnaires assessing functional ability Bath Ankylosing Spondylitis Functional Index (BASFI). This questionnaire includes 10 questions; eight evaluate activities related to the condition of the spine and two questions evaluate the patient's ability to cope with daily life (normal value $\leq 4$, range $0-10$ ). In the course of their medical appointment, each patient was invited to participate in this study; only patients with residence in urban areas and with a frequent clinical follow up was include. Patients with other spondyloarthropathies or hepatitis B or C were excluded.

No symptoms or signs of Toxocara infection were identified at this point. Initial assessment included collection of demographic information by questionnaire. Those patients with other spondyloarthropathies or hepatitis B or C were excluded. The control group was formed by 77 samples from healthy individuals (46 female and 31 male; mean \pm SD age: $30 \pm 15$ years).

\section{Methodology}

A total of $5 \mathrm{ml}$ of blood sample were collected from each patient. Serum samples were separated and then stored at $-20^{\circ} \mathrm{C}$. Blood tests included the identification of human leukocyte antigen B27 (HLA-B27), Erythrocyte Sedimentation Rate (ESR; Wintrobe, normal value 0-20 $\mathrm{mm} / \mathrm{h}$ ) and, C-Reactive Protein (CRP; immunoturbidimetry method Roche/Hitachi 912, Roche Diagnostic Corporation, Indianapolis, IN, USA, normal value $\leq 10 \mathrm{mg} / 1)$. Antibodies to Toxocara canis or Ascaris lumbricoides antigens were determined by an inhouse Enzyme-Linked Immunosorbent Assay (ELISA). Antibodies to Toxocara and Ascaris were determined in order to discard unspecific results by the cross-reaction between antigens. Assays were performed as previously described (Jiménez-Balderas et al., 2012). Briefly, antigens were prepared of adult worms collected from natural infections. A crude extract was prepared from $A$. lumbricoides and the excretory and secretory products were obtained from Toxocara canis. Soluble antigens were diluted at $0.003 \mathrm{mg} / \mathrm{mL}$ in $100 \mathrm{mM}$ carbonatebicarbonate buffer, $\mathrm{pH}$ 9.6. Flat-bottom polystyrene plates (Corning-Costar, Tewksbury, MA, USA) were coated with $0.1 \mathrm{~mL} /$ well of antigen solution then, incubated overnight at $4^{\circ} \mathrm{C}$. After remove the antigen solution, the plate was washed three times with 0.1 $\mathrm{mL} /$ well of $0.01 \mathrm{M}$ phosphate-buffered $0.15 \mathrm{M}$ saline (PBS) pH 7.2 containing $0.05 \%$ Tween 20 (PBS-T). Wells were blocked with $0.1 \mathrm{ml} /$ well of $1 \%$ nonfat milk during $2 \mathrm{~h}$ at $37^{\circ} \mathrm{C}$. Afterward, the washing process was repeated. Each serum sample was tested in triplicate. Serum sample was diluted 1:500 in PBS-T and 0.1 ml per well was dispensed. The plate was incubated for $2 \mathrm{~h}$ at $37^{\circ} \mathrm{C}$. The washing process was repeated. Anti-human IgG-horseradish peroxidase conjugate (ZymedInvitrogen, Camarillo, CA, USA) diluted 1:4,000 in PBS-T was added and incubated for $2 \mathrm{~h}$ at $37^{\circ} \mathrm{C}$. After washing, the reaction was developed. A substrate solution was prepared with o-phenylenediamine (SigmaAldrich, St. Louis, MO, USA) and $\mathrm{H}_{2} \mathrm{O}_{2}$ dissolved in 75 $\mathrm{mM}$ phosphate-citrate buffer, $\mathrm{pH} 5$ and, $0.1 \mathrm{ml}$ was added to each well. The enzyme reaction was terminated with $0.1 \mathrm{~mL} /$ well of $2 \mathrm{M} \mathrm{H}_{2} \mathrm{SO}_{4}$. Absorbency values were determined at $490 \mathrm{~nm}$. The serological parameters (e.g., cut off, sensitivity and specificity) were previously calculated and reported. Respect to the serological parameters for Ascaris assay, sensitivity was of $90.90 \%$, specificity $98.70 \%$ and cutoff 0.45 while, for Toxocara sensitivity was 80.77 , specificity 97.40 and cutoff 0.35 (Jiménez-Balderas et al., 2012).

\section{Statistical Analysis}

The Mid-p exact tests as well as the Odds Ratio (OR) and their 95\% Confidence Intervals (CI) between patients were used to analyze group differences. Otherwise, statistical analysis was performed using the statistical package Epi-Epidemiology ver. 2 (http://www.openepi.com). A p-value $<0.05$ was considered significant. The linear regression and the student's $\mathrm{T}$ test were also used to determine the correlation between the level of antibodies to helminthes and the ESR and CPR parameters.

\section{Results}

Data regarding the demographic characteristics of Ankylosing Spondylitis (AS) patients are show in Table 1. The mean \pm SD age of all patients was of $39.7 \pm 15.1$ years and, the mean \pm SD age at onset of disease was of $24.6 \pm 11.6$ years; the disease duration was $14.6 \pm 13.6$ 
years. At time of the study, 35/36 patients were administered with anti-inflammatory non-steroidal drugs; additionally, $15 / 36$ patients were administered only with one drug (3 with etanercept, 11 with sulfasalazine [SSZ] and 1 with methotrexate [MTX]), $5 / 36$ with two drugs (3 with MTX + SSZ, 2 with SSZ + etanercept) and 1/36 patient with 3 drugs (MTX + SSZ + etanercept). Specific IgG antibodies to Toxocara were determined in $25 \%(9 / 36)$ of the AS serum samples and, for Ascaris in $2.7 \%(1 / 36)$ of the samples. The positive sample for Ascaris was no positive for Toxocara. In the healthy group the seropositive was of $2.59 \%$ and $1.3 \%$ respectively. A correlation of AS and antibodies to Toxocara were observed ( $\mathrm{p}=0.0005432$; Mid- $\mathrm{p}$ exact, two tails. Odds Ratio: 2.703-87.27) but, the level of antibodies was not associated with the disability of AS (BASFI, CRP or ESR) neither to the HLA-B27 antigen (Table 2). The HLA-B27 antigen was positive in $62.5 \%$ (20/32) of AS patients, which 7 were female and 13 were male; no data about HLA-B27 antigen were available in 4 AS patients. No correlation was observed between the presence of HLA-B27 antigen and the presence of antibodies to Toxocara (0.6265; Mid-P exact, two tails). The BASFI was elevated in $74 \%$ of AS patients (6.4 \pm 1.5 ; normal value $\leq 4$, range $0-10)$, but no correlation was observed between the BASFI and the levels of antibodies to Toxocara (0.3708; Mid-P exact, two tails). The mean value of the Erythrocyte Sedimentation Rate (ESR) was of $16.9 \pm 12.8 \mathrm{~mm} / \mathrm{h}$ which was according to the normal values $(0-20 \mathrm{~mm} / \mathrm{h})$, since average values in healthy men are $<15 \mathrm{~mm} / \mathrm{h}$ and, in healthy females, they are somewhat higher, $<20$ $\mathrm{mm} / \mathrm{h}$. Although some AS patients have ESR over the normal values, no differences were observed between AS patients with or without antibodies to Toxocara ( $\mathrm{p}$ $=0.1058$; Student's T test). The mean value of $\mathrm{C}$ reactive protein in the AS patients was of $6.8 \pm 4.2$ (normal value $\leq 10 \mathrm{mg} / \mathrm{L}$ ), no differences were between AS patients with or without antibodies to Toxocara $(\mathrm{p}=0.0600$; Student's T test).

Evaluation of Ankylosing Spondylitis (AS) discapacity included the patient self-assessment Bath Ankylosing Spondylitis Functional Index (BASFI), identification of human leukocyte antigen B27 (HLAB27), Erythrocyte Sedimentation Rate (ESR) and levels of C-Reactive Protein (CRP). LR = Linear Regression.

\section{Discussion}

Human toxocariosis, usually caused by Toxocara canis, is an important health problem in developing countries (Magnaval et al., 2001). Data here obtained show that seropositivity to Toxocara in patients with AS is $25 \%$, which is in accordance with the observation that the seroprevalence of toxocariosis varies between 1.8 to $58.3 \%$ depending on country and study group (Macpherson, 2013). In addition, our results show a $T$. canis seroprevalence of $2.59 \%$ in the control group. The above discrepancies may be due to the fact that the seroprevalence of toxocariosis varies depending on country.

Table 1. Demographic characteristics of ankylosing spondylitis patients

\begin{tabular}{lll}
\hline & AS patients $(\mathrm{n}=36)$ & Healthy group $(\mathrm{n}=77)$ \\
\hline Gender (female/male) & $14 / 22$ & $31 / 46$ \\
Mean \pm SD age & $39.7 \pm 15.1$ & $30 \pm 15$ \\
Mean \pm SD age at onset of AS & $24.6 \pm 11.6$ & -- \\
Disease duration (years) & $14.6 \pm 13.6$ & --- \\
Toxocara seropositive $(+/-)$ & $(9 / 36)^{*}$ & $(2 / 77)$ \\
Ascaris seropositive $(+/-)$ & $(1 / 36)$ & $(1 / 77)$ \\
\hline
\end{tabular}

*Statistical differences were calculated with the Mid-p exact, two tails $(\mathrm{p}=0.0005432)$, Odds Ratio CMLE value $=12.18(2.703-87.27)$

Table 2. Relationship between the ankylosing spondylitis disability and the level of antibodies to Toxocara

\begin{tabular}{|c|c|c|c|c|c|}
\hline & \multirow[b]{2}{*}{ Group mean } & \multicolumn{2}{|c|}{ Antibodies to Toxocara } & \multicolumn{2}{|c|}{ Statistical data } \\
\hline & & Positive & Negative & Mid-P exact & LR \\
\hline HLA-B27 & $62.5 \% *(n=20 / 32)$ & $(5 / 7)$ & $(15 / 25)$ & 0.6265 & --- \\
\hline BASFI & $5.3 \pm 2.2$ & $6.6 \pm 2.7$ & $5.1 \pm 2.1$ & 0.3708 & 0.119 \\
\hline \multicolumn{6}{|c|}{ Student's $T$ test } \\
\hline CRP (mg/L) & $6.8 \pm 4.2$ & $4.0 \pm 2.5$ & $7.4 \pm 4.3$ & 0.06 & 0.0052 \\
\hline $\operatorname{ESR}(\mathrm{mm} / \mathrm{h})$ & $16.9 \pm 12.8$ & $26.2 \pm 12.2$ & $14.8 \pm 12.2$ & 0.1058 & 0.2345 \\
\hline
\end{tabular}

*Data were no available in four patients

Evaluation of Ankylosing Spondylitis (AS) discapacity included the patient self-assessment Bath Ankylosing Spondylitis Functional Index (BASFI), identification of human leukocyte antigen B27 (HLA-B27), Erythrocyte Sedimentation Rate (ESR) and levels of CReactive Protein (CRP). LR = Linear Regression 
Since data about the relationship between antibodies to Toxocara and the disability of ankylosing spondylitis are scarce, we decide to study a limited number of AS patients in an exploratory form. Although it is know that the analysis of small samples provide limited conclusions also, it is know that a limited number of AS patients are attending in a tertiary health care hospital. At this level of care, the number of AS patients is over 150 per year and, only $40 \%$ of them are urban residents and have a frequent follow-up (F.J. Jimenez-Balderas, unpublished data). The limited number of AS cases in medical attendance is explained considering that in Mexico there are no systematic studies regarding on the prevalence and distribution of AS. The AS prevalence is estimated with basis on the prevalence of HLA-B27 antigen, i. e., between 0.5 and $1 \%$ (Burgos-Vargas et al., 2009). Thus, in accordance with the Mexican population estimated in $2013 \quad(119,000,000$ inhabitants), a proportion of 0.005 to $0.01 \mathrm{AS}$ patients cases per capita (equivalent to one case for each 100 to 200 inhabitants) is estimated, which is a low frequency compared with the $7.5 \%$ prevalence of diabetes mellitus in adults (Olaiz-Fernández et al., 2007).

In México, T. canis is the most common ascarid in dogs but in humans, the infecting nematode larvae are unable to complete their own developmental life cycle and propagation (Hotez and Wilkins, 2009). The clinical symptoms vary as a consequence of larvae migration, ranging from asymptomatic forms to those with severe organ injuries (Overgaauw and van-Knapen, 2013). The observation that our patients never had a clinical picture of systemic toxocariosis and has normal eosinophil counts is consistent with previous reports showing that most patients with systemic toxocariosis are asymptomatic (Despommier, 2003). These data are also in perfect accordance with a previous report showing that the absence of eosinophilia does not exclude toxocariosis (Taylor et al., 1988). In the absence of parasitological evidence of infection, immunological methods play a relevant role in the diagnosis of toxocariosis. Currently, the diagnosis of toxocariosis is made by detection of antibodies directed against the $T$. canis antigens using the sensitive technique ELISA (Elefant et al., 2006). In this study, we use an ELISA previously standardized by us, the serological parameters were of $80.77 \%$ for diagnostic sensitivity and $97.40 \%$ for specificity (Jiménez-Balderas et al., 2012).

Although Western blotting procedure could be more suitable for the serologic diagnosis of toxocariosis, the ELISA has been particularly recommended in seroepidemiological studies (Radman et al., 2000; Elefant et al., 2006). Further studies are needed to determine the reactivity of AS serum samples by Western blotting to identify the existence of patterns that could be used in diagnosis. Indeed it would be helpfulness, determine the presence of serological antigens to determine active infections.
During the evolution of the asymptomatic toxocariosis, the detection of antibodies against the $T$. canis depends on the number of infecting larvae (Despommier, 2003). In this study, the detected antibodies in some AS patients, show that these patients were in contact with the parasite, however no symptoms of toxocariosis was clinical observed during the study.

There are only sporadic reports on the relationship between disease activity and parasitic infection in patients with rheumatologic syndromes. Williams and Roy (1981) have reported a case of arthritis associated with Toxocara infection. Furthermore, Peng (2002) has reported that potential parasitosis must be considered in patients with rheumatic syndromes. More recently, data from Richter et al., (2006) have found that in some individuals arthritis may be due to helminthes, such as Strongyloides stercoralis. A study conducted by Kuk et al. (2006) reported 3.2\% Toxocara seropositivity in AS patients. These studies indicate that in some rheumatic manifestations parasitic infection may underlie the clinical presentation. Although in this study, Toxocara positivity was higher than in the control group, the levels of antibodies to Toxocara were not associated with the HLA-B-57 antigen neither with the disability caused by the AS, although the $74 \%$ of AS patients had high values of BASFI (6.4 \pm 1.5$)$ with normal levels of CRP and ESR. Additionally, our data demonstrated no significant difference in the seroprevalence to A. lumbricoides (which has a higher frequency of cross-reaction with $T$. canis) when compared between in AS patients and control group. At present, there are no published data on this issue from a group of Mexican patients. These data may represent an important report, since no systematic reports about incidence of toxocariosis is found in Mexico. Toxocara investigations should be undertaken to determine whether our AS patients have risk factors for parasitic infection, such as their immunocompromised state and frequent contacts with dogs at home.

In conclusion, we investigated the possible association between the AS disease and the presence of antibodies to Toxocara in Mexican patients. We found that Toxocara seroprevalence was higher in patients with AS than in healthy individuals but antibodies were not associate to HLA-B-57 antigen neither with the disability caused by the AS. Our results suggest a minor role of toxocariosis involved in the pathology of the AS in Mexico but since limited conclusions could be obtained with the analysis of small samples further larger-scale studies are needed to determine the role of Toxocara in the AS prognosis.

\section{Acknowledgment}

We would like to express our gratitude to the staff at Centro Medico Nacional Siglo XXI, Instituto Mexicano del Seguro Social for their helpfulness during this study. P. Méndez-Samperio is a fellow in the programs of 
Stimuli Researchers Performance and, Operation and Development Committee of Academic Activities, National Politecnic Institute, in addition to the program of National System of Researchers, National Council of Science and Technology. J.-L. de-la-Rosa-Arana is a fellow at the National System of Researchers, National Council of Science and Technology.

\section{Author's Contributions}

All authors equally contributed in this work.

\section{Ethic}

This article is original and contains unpublished material. The corresponding author confirms that all of the other authors have read and approved the manuscript and no ethical issues involved.

\section{References}

Anderson, J.J., G. Baron, D. van der Heijde, D.T. Felson and M. Dougados, 2001. Ankylosingspondylitis assessment group preliminary definition of shortterm improvement inankylosing spondylitis. Arthritis Rheum., 44: 1876-1886.

DOI: 10.1002/1529-0131(200108)

Bocanegra, T.S. and F.B. Vasey, 1993. Musculoskeletal syndromes in parasitic diseases. Rheum. Dis. Clin. North Am., 19: 505-513. PMID: 8502785

Burgos-Vargas, R., C. Abud-Mendoza, E. Díaz-Jouanen, M.A. Garza-Elizondo and G. Medrano-Ramírez et al., 2009. Fundamentos para el tratamiento de la espondilitis anquilosante y su efecto en la reumatología mexicana. Gac. Méd. Méx., 145: 41-49.

Calin, A., S. Garrett, H. Whitelock, L.G. Kennedy and J. O'Hea et al., 1994. A new approach to defining functional ability inankylosing spondylitis: The development of the bath ankylosing spondylitis functional index. J. Rheumatol., 21: 2281-2285. PMID: 7699629

Despommier, D., 2003. Toxocariasis: Clinical aspects, epidemiology, medical ecology and molecular aspects. Clin. Microbiol. Rev., 16: 265-272. DOI: 10.1128/CMR.16.2.265-272.2003

Elefant, G.R., S.H. Shimizu, M.C. Arroyo-Sánchez, C.M. Abe-Jacob and A.W. Ferreira, 2006. A serological follow-up of toxocariasis patients after chemotherapy based on the detection of $\mathrm{IgG}, \mathrm{IgA}$ and IgE antibodies by enzyme-linked immunosorbent assay. J. Clin. Lab. Anal., 20: 164-172.

DOI: $10.1002 /$ jcla.20126

Garrett, S., T. Jenkinson, L.G. Kennedy, H. Whitelock and P. Gaisford et al., 1994. A new approach to defining disease status in ankylosing spondylitis: The bath ankylosing spondylitis disease activity index. J. Rheumatol., 21: 2286-2291.

PMID: 7699630
Hotez, P.J. and P.P. Wilkins, 2009. Toxocariasis: America's most common neglected infection of poverty and a helminthiasis of global importance? PLoS Negl. Trop. Dis., 3: e400- e400. DOI: 10.1371/journal.pntd.0000400

Jiménez-Balderas, F.J., A. Camargo-Coronel, J. GarcíaJaimes, A. Zonana-Nacach and I. AlcantaraAnguiano et al., 2012. A study on parasites in Mexican rheumatic disease patients. J. Egypt Soc. Parasitol., 42: 271-280. PMID: 23214207

Kuk, S., S. Ozgocmen and S. Bulut, 2006. Seroprevalance of Toxocara antibodies in multiple sclerosis and ankylosing spondylitis. Indian J. Med. Sci., 60: 297-299. DOI: 10.4103/0019-5359.26605

Macpherson, C.N., 2013. The epidemiology and publichealth importance of toxocariasis: A zoonosis of global importance. Int. J. Parasitol., 43: 9991008. DOI: 10.1016/j.ijpara.2013.07.004

Magnaval, J.F., L.T. Glickman, P. Dorchies and B. Morassin, 2001. Highlights of human toxocariasis. Korean J. Parasitol., 39: 1-11. DOI: $10.3347 / \mathrm{kjp} .2001 .39 .1 .1$

Martínez, A., C. Pacheco-Tena, J. Vázquez-Mellado and R. Burgos-Vargas, 2004. Relationship between disease activity and infection in patients with spondyloarthropathies. Ann. Rheum. Dis., 63: 1338-1340. DOI: 10.1136/ard.2003.011882

Oge, S. and H. Oge, 2000. Prevalence of Toxocara spp.eggs in the soil of public parks in Ankara, Turkey. Dtsch. Tierarztl Wochenschr, 107: 72-75. PMID: 10743338

Olaiz-Fernández, G., R. Rojas, C.A. Aguilar-Salinas, J. Rauda and S. Villalpando, 2007. Diabetes mellitus en adultos mexicanos. Resultados de la Encuesta Nacional de Salud 2000. Salud Pública Méx., 49: S331-S337.

DOI: $10.1590 / \mathrm{S} 0036-36342007000900004$

Overgaauw, P.A. and F. van-Knapen, 2013. Veterinary and public health aspects of Toxocara spp. Vet. Parasitol., 193: 398-403. DOI: 10.1016/j.vetpar.2012.12.035

Paul, I.R., E.S. Mitchell and A.L. Bell, 1988. Salmonella reactive arthritis in established ankylosing spondylitis. Ulster Med. J., 57: 215-217. PMID: 3232256

Peng, S.L., 2002. Rheumatic manifestations of parasitic diseases. Semin. Arthritis Rheum., 31: 228-247. PMID: 11836656

Radman, N.E., S.M. Archelli, R.D. Fonrouge, M. del VGuardis and O.R. Linzitto, 2000. Human toxocarosis. Its seroprevalence in the city of $\mathrm{La}$ Plata. Mem. Inst. Oswaldo Cruz, 95: 281-285. DOI: $10.1590 /$ S0074-02762000000300001

Richter, J., I. Müller-Stöver, H. Strothmeyer, K. Göbels and M. Schmitt et al., 2006. Arthritis associated with Strongyloides stercoralis infection in HLA B27-positive African. Parasitol. Res., 99: 706-707. DOI: $10.1007 / \mathrm{s} 00436-006-0225-9$ 
Romero-Núñez, C., G.D. Mendoza-Martínez, S. YáñezArteaga, M. Ponce-Macotela and P. BustamanteMontes et al., 2013. Prevalence and risk factors associated with Toxocara canis infection in children. Scientific World J., 2013: 572089-572089. DOI: $10.1155 / 2013 / 572089$

Sieper, J., M. Rudwaleit, M.A. Khan and J. Braun, 2006. Concepts and epidemiology of spondyloarthritis. Best Pract. Res. Clin. Rheumatol., 20: 401-417. DOI: 10.1016/j.berh.2006.02.001

Taylor, M.R., C.T. Keane, P. O'Connor, E. Mulvihill and C. Holland, 1988. The expanded spectrum of toxocaral disease. Lancet, 1: 692-695.

PMID: 2895221
Williams, D. and S. Roy, 1981. Arthritis and arthralgia associated with toxocaral infestation. Br. Med. J., 283: 192-192. DOI: 10.1136/bmj.283.6285.192

Yli-Kerttula, T., R. Tertti and A. Toivanen, 1995. Tenyear follow up study of patients from a Yersinia pseudotuberculosis III outbreak. Clin. Exp. Rheumatol., 13: 333-337. PMID: 755456

Zochling, J., 2008. Assessment and treatment of ankylosing spondylitis: Current status and future directions. Curr. Opin. Rheumatol., 20: 398-403. DOI: 10.1097/BOR.0b013e3283028328 